\title{
Role of hesperetin in LDL-receptor expression in hepatoma HepG2 cells
}

\author{
Nora A. Bawazeer ${ }^{1}$, Hani Choudhry², Mazin A. Zamzami ${ }^{3}$, Wesam H. Abdulaal ${ }^{3}$, Bruce Middleton ${ }^{4}$ \\ and Said S. Moselhy, $5,6^{*}$
}

\begin{abstract}
Background: High plasma concentration of low-density lipoprotein cholesterol (LDL-c) plays a significant role in the incidence of atherosclerosis and coronary heart diseases. The aim of this study was to investigate the mechanism by which the citrus flavonoid, hesperetin, regulates the LDL receptor (LDLr) gene in the human liver using the human hepatoma cell line, HepG2.

Methods: Luciferase reporter gene assays were performed (in the absence of lipoprotein) to measure the activity of the LDLr promoter and the promoters of the sterol regulatory element binding protein (SREBP) transcription factors that control the LDLr promoter.

Results: Only SREBP-1 promoter activity was significantly increased $4 \mathrm{~h}$ after exposure to $200 \mu \mathrm{M}$ hesperetin. However, after $24 \mathrm{~h}$ incubation with $200 \mu \mathrm{M}$ hesperetin, the activities of all the promoter-constructs, SREBP-1a, -1c, -2 and LDLr, were significantly increased. The effects of $200 \mu \mathrm{M}$ hesperetin on elevating LDLr mRNA levels were possibly due to regulation of LDLr gene transcription by SREBP-la and SREBP-2.

Conclusions: We conclude that $200 \mu \mathrm{M}$ hesperetin was likely to have stimulated LDLr gene expression in human hepatoma HepG2 cells via increased phosphorylation of PI3K andERK1/2, which increased SREBP-1a and SREBP-2 mRNA levels and enhanced the maturation of the encoded proteins. This may lead to lower plasma LDL cholesterol; therefore, diets supplemented with hesperidin might provide cardio-protective effects and reduce mortality and morbidity from coronary heart diseases.
\end{abstract}

Keywords: LDL-receptor, Hesperetin, HepG2 cell line

\section{Background}

High levels of plasma LDL-c are associated with accelerated atherosclerosis [1]. There is strong evidence supporting the involvement of oxidized LDL in cholesterol loading of macrophages, foam cell formation and atherogenesis [2]. The antioxidant properties of flavonoids result from the formation of stable radicals, due to electronic delocalization through the hydroxyaromatic groups in the $\mathrm{A}, \mathrm{B}$ and $\mathrm{C}$ rings. It has been reported that biological activity of flavonoids, which are directly related to electronic delocalization, may be affected by the presence/absence of

\footnotetext{
* Correspondence: moselhy6@hotmail.com

${ }^{5}$ Department of Biochemistry, Faculty of Science, King Abdulaziz University, Jeddah, Saudi Arabia

${ }^{6}$ Department of Biochemistry, Faculty of Science, Ain shams University, Cairo, Egypt

Full list of author information is available at the end of the article
}

the $\mathrm{C} 2-\mathrm{C} 3$ double bond, the position of hydroxyl groups or the planarity of the molecular structure [3].

Oxidation of LDL by macrophage free radicals leads to depletion of endogenous $\alpha$ - tocopherol levels causing the level of lipid hydroperoxides to rise. As a result, macrophages uptake of oxidized LDL is increased. Although it is believed that flavonoids can inhibit LDL oxidation by macrophages, the mechanism is unknown. However, several possibilities may explain flavonoid function. One possibility is that flavonoids protect $\alpha$ tocopherol from oxidized LDL from being consumed. This may occur either by scavenging free radicals or by converting $\alpha$-tocopheroxyl radicals into $\alpha$-tocopherol. Another possibility is that flavonoids may diminish the formation or release of free radicals by cells. In addition, flavonoids may inhibit LDL oxidation by scavenging superoxide anions, hydroxyl radicals or lipid peroxyl 
radicals. It has also been found that flavonoids have the ability to bind iron and copper [4].

Cholesterol feeding in animals can reduce the specific binding of LDL to hepatic membranes and experiments with cultured rat hepatocytes have suggested that this regulation is mediated by the uptake of cholesterol from exogenous lipoprotein via the LDLr, as is the case in cultured human skin fibroblasts. However, human hepatoma cells express LDL receptor activity in the presence of lipoproteins, suggesting that the suppression of LDLractivity in hepatocytes is less responsive to the external concentration of lipoprotein cholesterol than in fibroblasts [5].

Hesperetin belong to a class of flavonoids called flavanones. Flavanones occur almost exclusively in citrus fruits. Although the highest concentrations are found in the solid tissues, several hundred milligrams per liter are present in the juice. Hesperidin (hesperetin-7-rutinoside) is the major flavonoid of oranges, found largely as glycosides, which are hydrolyzed to their active forms by intestinal bacteria [6] Sweet orange juice contains narirutin (30-84 mg/L) and hesperidin (235-407 mg/L) [7-9]. SREBPs are members of the basic helix-loop- helix-leucine zipper (bHLHZip) family of transcription factors thatdirectly activate the transcription of more than 30 genes dedicated to the biosynthesis and uptake of cholesterol, fatty acid, triglycerides and phospholipids.

However, in the liver, SREBPs also regulate plasma lipoproteins and bile micelle synthesis genes [10]. Several distinct genes of both cholesterol and fatty acid metabolism aredirectly activated by SREBPs in cultured cells [11]. In vivo, genes of cholesterol metabolism are activated by SREBP-2, while genes of fatty acid and triglyceride metabolism are activated by SREBP-1c [12].

Although plant flavonoids have many potent biological properties, for example to lower blood cholesterol and as anticancer, antiviral, antioxidant drugs, their mechanisms of action have not been fully elucidated. The aim of this study was to investigate the mechanism(s) by which hesperetin may regulate the activity of the LDLr promoter, in human liver using human hepatoma HepG2 cells and to investigate whether these compounds act via a SREBP-dependent mechanism or as a result of modulation of other signal transduction pathways.

\section{Methods}

\section{Cell culture and transfection}

HepG2 human hepatoma cells were obtained from the American type Culture Collection (ATCC). Cells were maintained in $10 \%$ Growth Medium (GM), consisting of Dulbecco's Modified Eagle's Medium (high glucose with $4500 \mathrm{mg} / \mathrm{L}$ glucoseand sodium bicarbonate without Lglutamine; DMEM; Sigma) supplemented with $10 \%$ (v/v) fetal Bovine serum (FBS; Sigma), antibiotics (penicillin 100U/ml, $100 \mu \mathrm{g} / \mathrm{mlstreptomycin} \mathrm{sulphate)} \mathrm{and} 2 \mathrm{mM} \mathrm{L-}$ glutamine (Sigma). Adherent HepG2 and McARH-7777 cells were maintained in monolayer culture in $75 \mathrm{~cm}^{2}$ flasks in $10 \% \mathrm{GM}$ and incubated at $37{ }^{\circ} \mathrm{C}$, in $5 \% \mathrm{CO}_{2}$ for HepG2 and $10 \% \mathrm{CO}_{2}$ for McARH-7777 cells. Fresh GM was added every 2 days and cells were sub-cultured once a week by trypsinisation when the cells were $70 \%-80 \%$ confluent. The medium was removed by aspiration and the cells washed with $3 \mathrm{ml}$ 1x EDTA/saline. One milliliter of $1 \mathrm{x}$ trypsin solution was added and the flask incubated at $37{ }^{\circ} \mathrm{C}$ for $2-3 \mathrm{~min}$. Ten milliliters of $10 \% \mathrm{GM}$ was added and the cells were harvested by centrifugation at $900 \times$ gfor $5 \mathrm{~min}$. The cell pellet was resuspended in fresh $10 \%$ GM. Cells were split $1: 2$ to $1: 7$ into $75 \mathrm{~cm}^{2}$ flasks for growth or into 6 -well plates $\left(9.6 \mathrm{~cm}^{2} /\right.$ well; IWAKI) for experiments. Hesperetin (purity: >98 \%, was purchased from Sigma).

\section{Transfection for dual-luciferase assay}

Cells were transiently transfected with $1 \mu \mathrm{g} /$ well human pLDLr Luc ${ }^{+}$, pSREBP-1a Luc+, pSREBP-1c Luc + and pSREBP-2 Luc $^{+}$using GeneJuice transfection reagent (Novagen) according to the manufacturer's protocol. Cells were then incubated in the transfection medium for $4 \mathrm{~h}$. Medium was then removed and cells were washed with $2 \mathrm{ml} /$ well basal DMEM. Cells were then exposed to DMSO as a vehicle or hesperetinin fresh $5 \mathrm{mg} / \mathrm{ml}$ Human lipoprotein-deficient serum (LPDS). After $24 \mathrm{~h}$ incubation, cells were lysed for Firefly Luciferase and protein assays.

\section{Dual-luciferase reporter assay system}

Aluminometer (TD-20/20) was programmed to perform a $2 \mathrm{~s}$ pre-measurement delay, followed by a 10 s measurement period for each reporter assay. One hundred microliters of LAR II was pre-dispensed into a luminometer tube and then $20 \mu \mathrm{l}$ of cell lysate was added. After mixing by pipetting two or three times, the tube was placed in the luminometer and the firefly luciferase activity measurement was recorded. Then, $100 \mu \mathrm{l}$ of Stop \& Glo Reagent was added and vortex-mixed briefly. The Renilla luciferase activity was measured.

\section{BioRad protein assay}

Cell lysates were diluted (1:20) in 1x PLB. Tenmicrolitersfrom each sample was assayed for protein concentration using Bovine Serum Albumin (BSA, Sigma) protein standards of known protein concentration $(0,1,2,3,4$ and $5 \mathrm{mg} / \mathrm{ml}$ ). Bio-Rad Reagent was diluted 1:5 (v/v) with distilled water, $200 \mu \mathrm{l}$ was added to each sample and to the standards in a 96-well plate (Corning Incorporated, Costar). The plate was then carefully mixed to remove bubbles and incubated for $5 \mathrm{~min}$ at room temperature and the absorbance was read using a Dynatech MR 5000 Microplate Reader at a wavelength of $595 \mathrm{~nm}$. 
Protein concentrations $(\mathrm{mg} / \mathrm{ml})$ were calculated from the standard curve and used to normalize the luciferase activity values [13].

\section{DNA quantitation}

A Gene Quant2 spectrophotometer (Pharmacia) or a NanoDrop ND-1000 Spectrophotometer (NanoDrop Technologies) was used to estimate the concentration of the double strand DNA by measuring absorbance at $260 \mathrm{~nm}$ and $280 \mathrm{~nm}$. The ratio of absorbencies was used to assess the purity of DNA. The absorbance at $260 \mathrm{~nm}$ was used to calculate DNA concentration using the following equation: Concentration $(\mu \mathrm{g} / \mathrm{ml})=$ dilution factor $\times \mathrm{A}_{260} \times 50 \mu \mathrm{g} / \mathrm{ml}$. A solution with O.D $D_{260}=1.0$ contains approximately $50 \mu \mathrm{g} /$ $\mathrm{ml}$ of double stranded DNA. Pure DNA preparations have a ratio at 260/280 of 1.8-2.0 (Qiagen, 2006).

\section{Polymerase chain reaction (PCR)}

A standard PCR protocol was used to amplify specific sequences of DNA for molecularanalysis.

\section{Statistical analysis}

The computer software program GraphPad Prism (GraphPad 4.01) was used for all data analysis. A one-way analysis of variance (ANOVA) was used to compare significant differences between groups. Post hoc Dunnett's or Bonferroni's Multiple Comparison tests were used. The Statistical significance was accepted if the null hypothesis was rejected with a $p<0.05$. Results are expressed as the mean \pm SEM of separate experiments. All analyses were carried out with $95 \%$ confidence intervals.

\section{Results}

Results presented in Fig. 1 show the effect of different hesperetin concentrations in lipoprotein deficient medium (LPDM) on the activity of pLDLr Luc + in human hepatoma HepG2 cells after $24 \mathrm{~h}$. HepG2 Cells were transfected with $1 \mu \mathrm{g} /$ well human pLDLr, which drives Firefly Luciferase. To assaythe pLDLr promoter response to different concentrations of hesperetin, $5 \mathrm{mg} / \mathrm{ml} \mathrm{LPDM}+2 \mu \mathrm{l} / \mathrm{ml}$ DMSO was used as vehicle. Cells were exposed to $25 \mu \mathrm{M}$, $50 \mu \mathrm{M}, 100 \mu \mathrm{M}, 150 \mu \mathrm{M}$ and $200 \mu \mathrm{M}$ hesperetin in fresh $5 \mathrm{mg} / \mathrm{ml} \mathrm{LPDM}$. After incubation for $24 \mathrm{~h}$, cells were harvested for Luciferase and protein assays. pGL3 Luciferase reporter-Basic and-Control vectorswere used to indicate the transfection efficiency. The difference between groups was evaluated by one-way ANOVA with Dunnett's Multiple Comparisons Test. The data represent an individual experiment, which was repeated twice. Values areexpressed as mean \pm SEM; $\mathrm{n}=3$ per treatment. Hesperetin at $25 \mu \mathrm{M}$ and $50 \mu \mathrm{M}$ increased pLDLr Luc + activity compared with the vehicle but the increase was not significant, while $100 \mu \mathrm{M}$, $150 \mu \mathrm{M}$ and $200 \mu \mathrm{M}$ hesperetin significantly up-regulated pLDLr Luc + activity after $24 \mathrm{~h}(* * * 00.01)$.

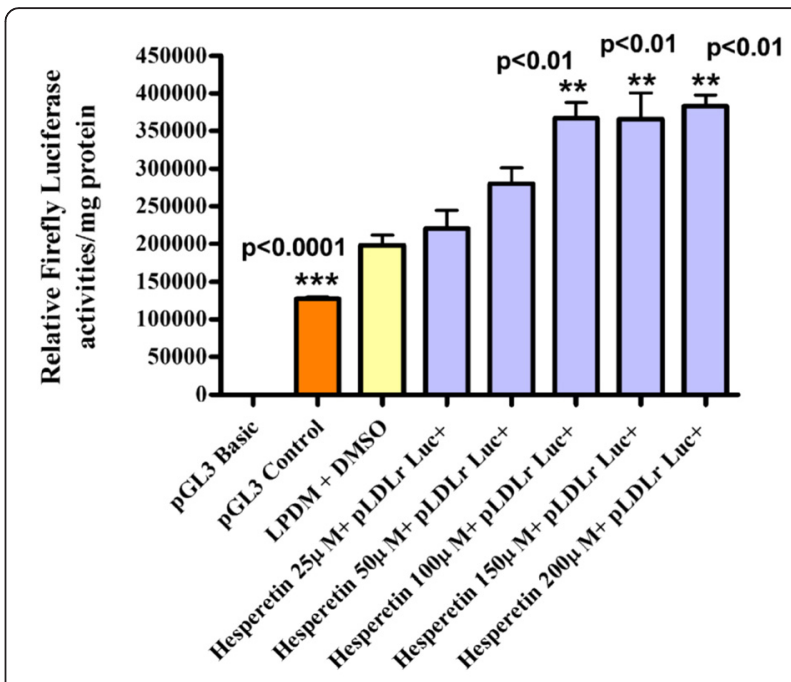

Fig. 1 The Effect of Different Hesperetin Concentrations in LPDM on the Activity of pLDLr Luc + in Human Hepatoma HepG2 Cells after $24 \mathrm{~h}$. HepG2 Cells were transfected with $1 \mu \mathrm{g} /$ well human pLDLr driving firefly luciferase. To assay the pLDLr promoter response to the different concentrations of hesperetin, $5 \mathrm{mg} / \mathrm{ml}$ $\mathrm{LPDM}+2 \mu \mathrm{l} / \mathrm{ml}$ DMSO was used as vehicle. Cells were exposed to $25 \mu \mathrm{M}, 50 \mu \mathrm{M}, 100 \mu \mathrm{M}, 150 \mu \mathrm{M}$ and $200 \mu \mathrm{M}$ hesperetin in fresh $5 \mathrm{mg} / \mathrm{ml}$ LPDM. After incubation for $24 \mathrm{~h}$, cells were harvested for luciferase and protein assays. pGL3 Luciferase reporter-Basic and -Control vectors were used to indicate the transfection efficiency. The difference between groups was evaluated by one-way ANOVA with Dunnett's multiple comparisons test. The data represent an individual experiment, which was repeated twice. Values were expressed as mean $\pm \mathrm{SEM} ; n=3$ per treatment

HepG2 cells were transiently transfected with the human PSREBP-1a promoter driving firefly luciferase. After transfection, spent medium was removed and cells were washed with $2 \mathrm{ml} /$ well basal DMEM. Cells were then exposed to DMSO vehicle or to $25 \mu \mathrm{M}, 50 \mu \mathrm{M}, 100 \mu \mathrm{M}$, $150 \mu \mathrm{M}$ and $200 \mu \mathrm{M}$ hesperetin in $5 \mathrm{mg} / \mathrm{ml}$ fresh LPDM. After incubation for $24 \mathrm{~h}$, the cells were lysed for luciferase and protein assays. Hesperetin at $25 \mu \mathrm{M}$ and $50 \mu \mathrm{M}$ caused a slight increase in the pSREBP-1a Luc + activitycompared with the vehicle. However, hesperetin concentrations of $100 \mu \mathrm{M}$ (* $p<0.05), 150 \mu \mathrm{M}(* p<0.05)$ and $200 \mu \mathrm{M}(* * p<0.01)$ significantly up-regulated pSREBP1a Luc + activity in HepG2 cells.

Figure 2 shows the effect of different hesperetin concentrations on the activity of pSREBP-2 Luc + in HepG2 cells $24 \mathrm{~h}$ after transfection with $1 \mu \mathrm{g} /$ well human pSREBP-2 driving firefly luciferase. $2 \mu \mathrm{l} / \mathrm{ml}$ DMSO was used as vehicle. Cells were exposed to $25 \mu \mathrm{M}, 50 \mu \mathrm{M}$, $100 \mu \mathrm{M}, 150 \mu \mathrm{M}$ and $200 \mu \mathrm{M}$ hesperetin. After incubation for $24 \mathrm{~h}$, cells were harvested for luciferase and protein assays.

The results (Fig. 3) also indicated that $200 \mu \mathrm{M}$ hesperetin significantly decreased the activity of the MTP promoter in HepG2 cells. Hesperetin at $200 \mu \mathrm{M}$ significantly 

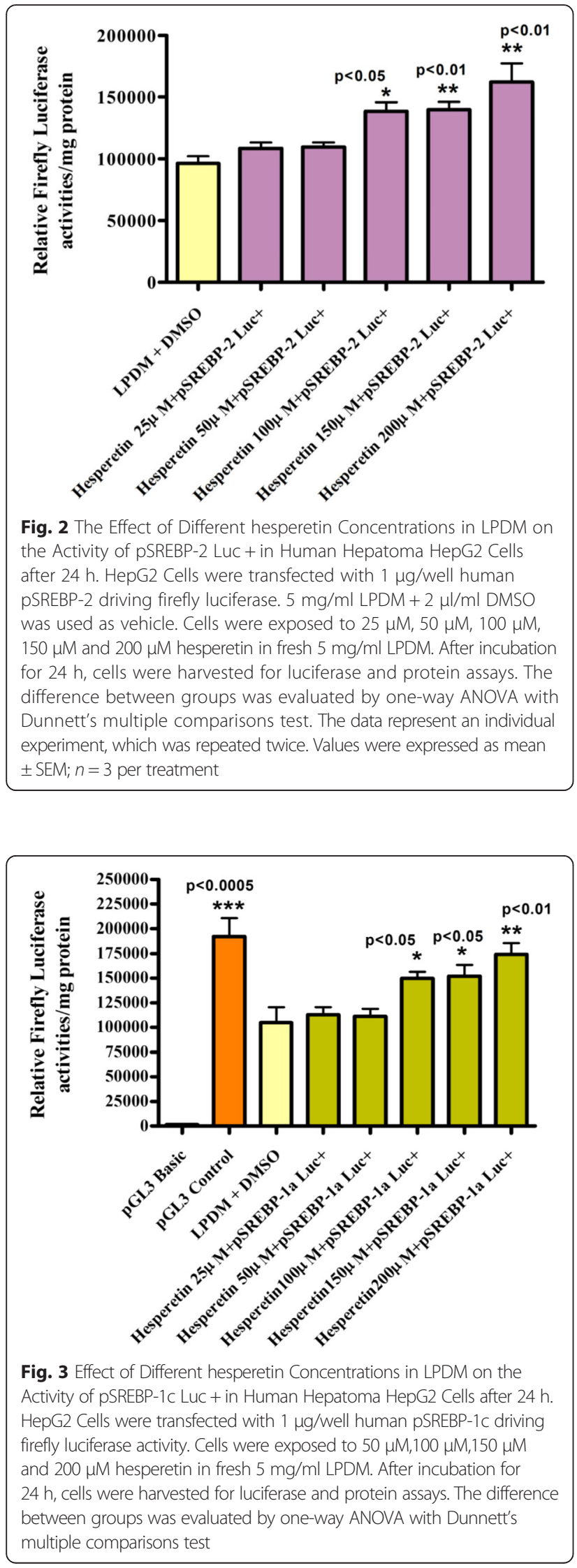

up-regulated the mRNA levels of both SREBP- 1a and LDLr mRNAs after 4, 8, 12 and $24 \mathrm{~h}$, while the levelsof SREBP-2 mRNA were significantly increased after 12 and $24 \mathrm{~h}$. However, the mRNA level of SREBP-1c was significantly down-regulated after 4, 8, 12 and $24 \mathrm{~h}$, while fatty acid synthase mRNA expression was significantly decreased after 8, 12 and $24 \mathrm{~h}$. Both HMG-CoA reductase and acetyl-CoA carboxylase- $\alpha$ mRNA levels were also significantly decreased after 12 and $24 \mathrm{~h}$ (Fig. 4).

\section{Discussion}

The regulation of hepatic LDL-c catabolism relies on the activity of the LDL receptor (LDLr) to maintain a steadystate plasma concentration of LDL-c [14]. In the human body, the liver is the most LDL-receptor abundant organ and accounts for $80 \%-90 \%$ of the total LDL clearance from plasma [15]. The identification of the sterol regulatory element binding protein (SREBP) transcription factors furthered understanding of cellular cholesterol homeostasis [16]. In vivo, SREBPs are found to be crucial for the synthesis and clearance of atherogenic lipoproteins and also for the highly activated transcription of several genes, including the LDLr [17].

SREBPs are members of the basic helix-loop-helix-leucine zipper (bHLH-Zip) family of transcription factors that directly activate the transcription of more than 30 genes dedicated to the biosynthesis and uptake of cholesterol, fatty acid, triglycerides and phospholipids [18].

SREBP-1a, SREBP-1c and SREBP-2 are the three major SREBP isoforms to have been identified. They are synthesized in the liver as precursors membrane-bound to the endoplasmic reticulum and nuclear envelope [19]. Low intracellular cholesterol concentration promotes atwostep proteolytic cleavage process for SREBP-l and SREBP2 precursors. As a result, transcriptionally active SREBP migrates to the nucleus where it strongly activates transcription of several genes involved in cholesterol and fatty acid synthesis [20]. LDLr uptake of cholesterol increases intracellular cholesterol, which inhibits the release of mature SREBP resulting in suppression of LDLr transcription [21]. Deletion of the acidic $\mathrm{NH}_{2}$-terminal region of SREBP, which is the transcriptional activation domain, prevented the transcriptional activation of the LDLr. High-level expression of LDLr is achieved when SREBP-1 and SREBP-2 bind to the sterol response element-1 (SRE-1) sequence and interact with repeat 3 of stimulating protein-1 (Sp1), thereby reducing elevated levels of plasma cholesterol [22]

In vivo studies revealed that SREBP-2 activates cholesterol metabolismgenes, whereas SREBP1c activated genes of fatty acid and triglyceride metabolism. However, SREBP1a seemed to activate both pathways. Consumption of fruits and vegetables can protect against the development of cardiovascular diseases [23]. Although plant flavonoids can act as anticancer, antiviral and antioxidant agents and 


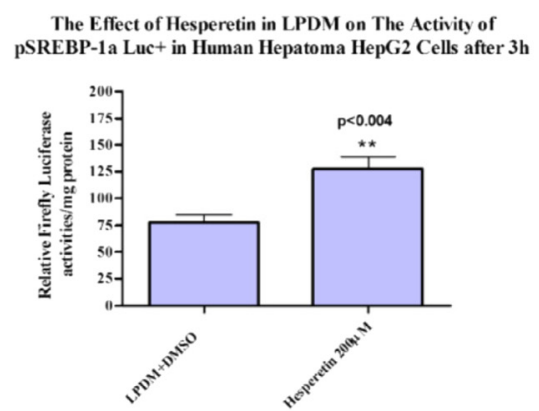

The Effect of Hesperetin in LPDM on The Activity of pSREBP-2 Luc+ in Human Hepatoma HepG2 Cells after $3 \mathrm{~h}$

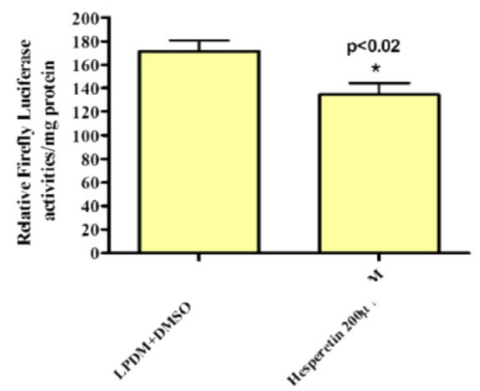

The Effect of Hesperetin in L.PDM on The Activity of pSREBP-1c Luc+ in Human Hepatoma HepG2 Cells after 3h

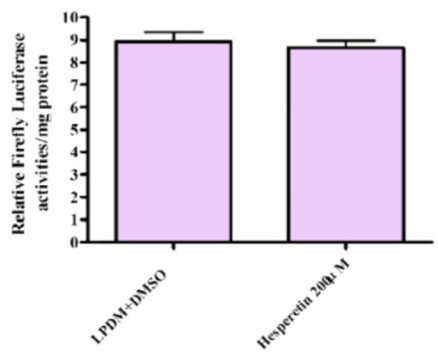

The Effect of Hesperetin in LPDM on The Activity of pLDLr Luc+ in Human Hepatoma HepG2 Cells after $3 \mathrm{~h}$

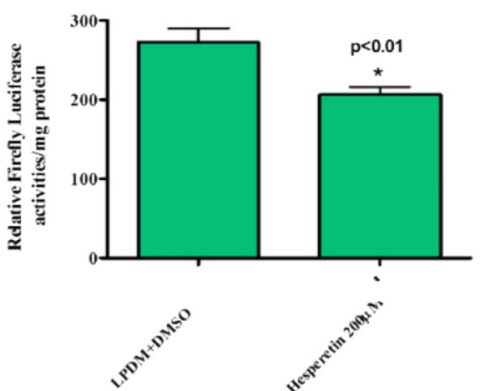

Fig. 4 Effect of hesperetin in LPDM on the Activity of Human pSREBP-1a Luc+, pSREBP-1c Luc+, pSREBP-2 Luc + and pLDLr Luc + in Human Hepatoma HepG2 Cells after $3 \mathrm{~h}$. HepG2 cells were transiently transfected in LPDM with $1 \mu \mathrm{g} /$ well human pLDLr Luc+,pSREBP-1a Luc+, pSREBP-1c Luc + or pSREBP-2 Luc + as described above. Firefly luminescence was normalized to total cellular protein to determine promoteractivity

can lower blood cholesterol, the mechanisms of these actions in most cases have not been fully elucidated [24].

As the liver plays a major role in cholesterol and lipid metabolism, human hepatoma HepG2 cells, a human liver-derived cell line [25], was used as a model to investigate the molecular mechanisms by which the citrus flavonoid, hesperetin, regulates hepatic activity of genes associated with cholesterol and lipid metabolism.

LDL cholesterol reduction occurs mainly via LDLr upregulation. LDLr expression is mainly regulated at the transcriptional levelvia SREBP-1a, -1c, and -2 [26]; therefore, to investigate the molecular mechanism by which hesperetin regulates LDLr transcription luciferase-reporter gene assays were performed to compare the transcriptional regulation of the SREBP-1a, -1c, and -2 promoters on the activity of the LDLr gene. Human lipoprotein-deficient serum (LPDS) was used to maximize LDLr activity.

Preliminary experiments were performed to examine LDLr promoter sensitivity to the addition of cholesterol or LPDM. Transient transfection data revealed that LDLr promoter activity was significantly elevated in cells incubated in LPDM as compared with complete growth medium. This was in agreement with several studies which revealed that LDLr transcription activity was activated in the absence of sterols [27]. The effect of hesperetin in LPDM on regulating the activity of LDLr, SREBP-1a, SREBP-1c and
SREBP-2 was dose-dependent with notable stimulation at $100 \mu \mathrm{M}$ and $200 \mu \mathrm{M}$ after $24 \mathrm{~h}$. Hesperetin at $200 \mu \mathrm{M}$ appeared to be potent in up-regulating all promoters investigated. Cell viability assays confirmed that $200 \mu \mathrm{M}$ hesperetin did not cause any harmful effect in HepG2 cells; therefore we used it in all our experiments.

Time-course transient transfection data indicated that early significant activation of SREBP-1a promoter was observed after $3 \mathrm{~h}$ incubation with $200 \mu \mathrm{M}$ hesperetin. However, the gene expression activities of LDLr, SREBP-1a, SREBP-1c and SREBP-2 were increased significantly after incubation for $24 \mathrm{~h}$ with $200 \mu \mathrm{M}$ hesperetin. Based on our findings we suggest that only SREBP-1a and SREBP-2 are involved in the regulation of LDLr expression in HepG2 cells as previously reported by many studies [28]. It would also appear that the SREBP-1c promoter is less likely to be involved in the regulation of LDLr expression in HepG2 cells because in previous studies its electively stimulated fatty acid synthesis and insulin-induced glucose metabolism [29]. The extremely low mean luciferase activity of the SREBP-1c promoter construct compared with the other constructs could be explained by reduced SREBP-1c mRNA expression and an undetectable level of SREBP-1c protein. These findings determined that $200 \mu \mathrm{M}$ hesperetin did not increase SREBP-1c promoter activity in HepG2 cells. Hesperetin at $200 \mu \mathrm{M}$ also significantly decreased 
the activity of the MTP promoter in Human Hepatoma HepG2 cells.

The investigation of mRNA levels by qRT-PCR (Taqman) assay in HepG2 cells revealed that $200 \mu \mathrm{M}$ hesperetin in LPDM significantly up-regulated the mRNA levels of both the SREBP- 1a and LDLr mRNAs after 4, 8, 12 and $24 \mathrm{~h}$, while the expression of SREBP-2 mRNA was significantly increased after 12 and $24 \mathrm{~h}$. However, the mRNA level of SREBP-1c was significantly down-regulated after 4, 8,12 and $24 \mathrm{~h}$, while the fatty acid synthase mRNA expression was significantly decreased after 812 and $24 \mathrm{~h}$. Both the HMG-CoA reductase and Acetyl-CoA Carboxylase- $\alpha$ mRNA expressions were also significantly decreased after 12 and $24 \mathrm{~h}$. Our results suggest that it is likely that the effects of $200 \mu \mathrm{M}$ hesperetin on elevating LDLr mRNA are due to regulation of gene transcription by SREBP-la and SREBP-2 in HepG2 cells because in the absence of sterols, high-level expression of the LDLr was achieved when SREBP-1 and SREBP-2 were bound to the SRE-1 sequence and interacted with Sp1 [30-32].

In this study, it is likely that the suppression effect of hesperetin on hepatic SREBP-1c mRNA levelsis associated with the reduction in mRNA levelsof both acetyl-CoA carboxylase and fatty acid synthase. Furthermore, $200 \mu \mathrm{M}$ hesperetin in LPDM had no effect on the SREBP-1a precursor form. However, they both caused a significant increase in the amount of SREBP-1a mature form which could be a result of phosphorylation by PI3K and ERK1/2. Thus, the effects of hesperetin upon the expression of the LDLr gene are likely to occur via an increased SREBP1a and SREBP-2 mRNA levels and increased maturation of the encoded proteins.

\section{Conclusion}

We conclude that, $200 \mu \mathrm{M}$ hesperetin is likely to stimulate LDLr gene expression via increase phosphorylation of PI3K and ERK1/2, which enhance mRNA levels of the transcription factors, SREBP-1a and SREBP-2, and increased their protein maturation in human hepatoma HepG2 cells. Since this may lead to lower plasma LDL cholesterol, diets supplemented with hesperetin may produce cardio-protective effects in humans and reduce mortality and morbidity from coronary heart diseases.

\footnotetext{
Abbreviations

DMEM, Dulbecco's Modified Eagle's Medium; GM, growth medium; HepG2, human hepatoma cell line; LDL-c, LDL cholesterol; LDLr, LDL receptor; LPDM, lipoprotein deficient medium; MAPK, mitogen-activated protein kinase; PI3K, phosphatidylinositol 3-kinase; SRE, sterol response element; SREBP, sterol regulatory element binding protein
}

\section{Acknowledgments}

The authors would like to thank Dr. Peter Jones and Dr. Alex Tarr, Medical School, Nottingham University, Nottingham, United Kingdom for their support and advice in statistical analysis.

\section{Funding}

This study was granted by grants from Taif University, Saudi Arabia under University's Graduated Research Fund.

\section{Availability of data and materials}

All data and materials are contained and described within the manuscript. The data set was deposited in publicly available repositories.

\section{Authors' contributions}

NB and BM: contributed conception, study design, data collection and analysis, and manuscript writing. SSM, HC, MZ and WA: made contributions to acquisition of data, interpretation of data and intellectual content.

All authors read and approved the final manuscript.

\section{Authors' information}

Dr. Nora Bawazir; assistant professor, Faculty of Home Economic, Taif University, Saudi Arabia. Dr. Hani Choudhry, Dr. Mazin Zamzami and Dr. Wesam Abdulaal before prof. said Moselhy are stuff members at biochemistry department, King Abdulaziz University, Jeddah, Saudi Arabia and Prof. Bruce Middleton, Department of Biochemistry, Medical School, Nottingham University, Nottingham, United Kingdom.

\section{Competing interests}

The authors declare that they have no competing interests.

\section{Consent for publication}

This information is not relevant.

Ethics approval and consent to participate

Not applicable her.

\section{Author details}

${ }^{1}$ Department of Home Economics, Taif University, Taif, Saudi Arabia. ${ }^{2}$ Department of Biochemistry, Faculty of Science, Cancer and mutagensis unit, Center of Innovation in Personalized Medicine, King Fahd Center for medical Research, King Abdulaziz University, Jeddah, Saudi Arabia. ${ }^{3}$ Department of Biochemistry, Cancer and mutagensis Unit, King Fahad Medical Research Center, KingAbdulaziz University, Jeddah, Saudi Arabia. ${ }^{4}$ Department of Biochemistry, Medical School, Nottingham University, Nottingham, UK. ${ }^{5}$ Department of Biochemistry, Faculty of Science, King Abdulaziz University, Jeddah, Saudi Arabia. ${ }^{6}$ Department of Biochemistry, Faculty of Science, Ain shams University, Cairo, Egypt.

Received: 26 September 2015 Accepted: 15 June 2016

Published online: 27 June 2016

\section{References}

1. Leelavinothan P, Kalist S. Beneficial effect of hesperetin on cadmium induced oxidative stress in rats: an in vivo and in vitro study. Eur Rev Med Pharmacol Sci. 2011;15:992-1002.

2. Choi EJ. Antioxidative effects of hesperetin against 7, 12dimethylbenz(a)anthracene-induced oxidative stress in mice. Life Sci. 2008:82:1059-64.

3. Botham KM, Mayes PA. 'Lipids of Physiologic Significance' in Harper's Illustrated Biochemistry, Murray, R.K., Granner,D.K., Mayes,P.A. and Rodwell,V.W. (eds.). TheMcGraw-Hill Companies, Inc.USA, 27th edition, 2006 a; 121-131.

4. Botham KM, Mayes PA. 'Lipid Transport and Storage' in Harper's Illustrated Biochemistry, Murray, R. K., Granner, D.K., Mayes, P.A. and Rodwell, V.W.(eds.). TheMcGraw-Hill Companies, Inc.USA, 27th edition, 2006 b; 217-229.

5. Botham KM, Mayes PA. 'Cholesterol Synthesis, Transport, and Excretion'in Harper's Illustrated Biochemistry, Murray, R.K., Granner, D.K., Mayes, P.A. and Rodwell, V.W. (eds.). The McGraw-Hill Companies, Inc.USA, 27th edition,2006 c; 230-240

6. Borradaile NM, Kuroska EM. Regulation of HepG2 cell apolipoprotein B metabolism by citrus flavones hespertina and naringnin. Lipid. 1999;34:591-598.

7. von Brasch L, Zang C, Haverkamp T, Schlechte H, Heckers H, Petrides PE. Molecular analysis of acute intermittent porphyria: mutation screening in 20 patients in Germany reveals 11 novel mutations. Blood Cells Mol Dis. 2004;32:309-14. 
8. Briggs MR, Yokoyama C, Wang X, Brown MS, L GJ. Nuclear protein that binds sterol regulatory element of low density lipoprotein receptor promoter. 1. Identification of Effect of Hesperetin and Naringenin on Hepatic Lipid Metabolism and Gene Expression the protein and delineation of its target nucleotide sequence. J Biol Chem, 1993;268:14490-14496

9. Nalini N, Aranganathan S, Kabalimurthy J. Chemopreventive efficacy of hesperetin (citrus flavonone) against 1, 2-dimethylhydrazine-induced rat colon carcinogenesis. Toxicol Mech Methods. 2012;22:397-408.

10. Brown MS, Goldstein JL. A receptor-mediated pathway for cholesterol homeostasis. Angew Chem In Ed England. 1986;25:583-660.

11. Kurowska E, Borrdaile N, Spence J, Karroll K. Hypocholesterolemic effects of dietary citrus juice in rabbit. Nutrition research. 2000;20:121-129.

12. Mullen E, Brown RM, Osborne TF, Shay NF. Soy isoflavones affect sterol regulatory element binding proteins (SREBPS) and SREBP regulated genes in HepG2 cells. J Nutrition. 2004;134:2942-7.

13. Manach C, Morand C, Gil-Izquierdo A, Bouteloup-Demange C, Remesy C. Bioavailability in humans of the flavanones hesperidin and narirutin after the ingestion of two doses of orange juice. Eur J Clin Nutr. 2003;57:235-42.

14. Brüning JC, Lingohr P, Gillette J, Hanstein B, Avci H, Krone W, Müller-Wieland D, Kotzka J. Estrogen receptor-a and Sp1 interact in the induction of the low densitylipoprotein receptor. J Steroid Biochem Mol Biol. 2003;86:113-21.

15. Bucci C, Serú R, Annella T, Vitell R, Lattero D, Bifulco M, Mondola P, Santillo M. Free fatty acids modulate LDL receptor activity in BHK-21 cells. Atherosclerosis. 1998;137:329-40

16. Bustin SA. Absolute quantification of mRNA using real-time reverse transcription polymerase chain reaction assays. J Mol Endocrinol. 2000;25:169-93.

17. Bustin SA. Quantification of mRNA using real-time reverse transcription PCR (RT-PCR): trends and problems. J Mol Endocrinol. 2002;29:23-39.

18. Carlo GD, Mascolo N, Izzo AA, Capasso F. Flavonoids: Old and New aspects of a class of natural therapeutic drugs. Life Sci. 1999;65:337-53.

19. Chait A, Bierman EL, Albers JJ. Low-density lipoprotein receptor activity in cultured human skin fibroblasts. Mechanism of insulin-induced stimulation. J Clinical Investigation. 1979;64:1309-19.

20. Chang R, Yang E, Chamblis D, Kumar A, Wise J, Mehta KD. In vivo role of the SP1 site neighboring sterol-responsive element-1 in controlling Low-density lipoprotein receptor gene expression. Biochem Biophys Res Commun. 1996:218:733-9.

21. Grundy SM, Cleeman Jl, Merz CN, Brewer HB, Clark LT, Hunninghake DB, Pasternak RC, Smith SC, Stone NJ. Implications of recent clinical trials forthe national cholesterol education program adult treatment panel III guidelines. Circulation. 2004;110:227-39.

22. Gurr Ml, Harwood JL, Frayn KN. 'Lipid transport' in Lipid biochemistry. BlackwellScience, 5th edition, 2002; 170-182.

23. Hagan DL, Kienzle B, Jamil H, Hariharan N. Transcriptional regulation of human andHamster microsomal triglyceride transfer protein genes. J Biol Chem. 1994:269:28737-44.

24. Hannah VC, Ou J, Luong A, Goldstein JL, Brown MS. Unsaturated fatty AcidsDown-regulate SREBP isoforms 1a and 1c by Two mechanisms in HEK-293 cells. J Biol Chem. 2001;276:4365-72.

25. Harborne JB, Williams CA. Advances in flavonoid research since 1992. Phytochemistry. 2000;55:481-504.

26. Hasty AH, Shimano H, Yahagi N, Amemiya-Kudo M, Perrey S, Yoshikawa T, Osuga J,Okazaki H, Tamura Y, lizuka, Y, Shionoiri F, Ohashi K, Harada K, Gotoda T, Nagai R. Sterol regulatory element-binding protein-1 is regulated by glucose at the transcriptional level. J Biol Chem. 2000;275:31069-77.

27. Ishibashi S, Yamada N. Sterol regulatory element-binding protein-1 IsRegulated by glucose at the transcriptional level. J Biol Chem. 2000;275:31069-77.

28. Heemers $\mathrm{HV}$, Verhoeven $\mathrm{G}$, Swinnen JV. Androgen activation of the SREBP pathway:current insights. Mol Endocrinol. 2006;20:2265-77.

29. Herz J. Deconstructing the LDL receptor a rhapsody in pieces. Nat Struct Biol. 2001;8:476-8.

30. Hirano Y, Yoshida M, Shimizu M, Sato R. Direct demonstration of rapid degradation of nuclear sterol regulatory element-binding proteins by the Ubiquitin-Proteasome pathway. J Biol Chem. 2001;276:36431-7.

31. Hirokane H, Nakahara M, Tachibana S, Shimizu M, Sato R. Bile acid reduces the secretion of very Low density lipoprotein by repressing microsomal triglyceride transfer protein gene expression mediated by hepatocyte nuclear factor-4. J Biol Chem. 2004;279:45685-92.

32. Hodgin JB, Maeda N. Minireview: estrogen and mouse models of atherosclerosis. Endocrinology. 2002;143:4495-501.

\section{Submit your next manuscript to BioMed Central and we will help you at every step:}

- We accept pre-submission inquiries

- Our selector tool helps you to find the most relevant journal

- We provide round the clock customer support

- Convenient online submission

- Thorough peer review

- Inclusion in PubMed and all major indexing services

- Maximum visibility for your research

Submit your manuscript at www.biomedcentral.com/submit
Biomed Central 